\title{
Correlation Research on the Self - Efficacy and Job Alienation of Clinical Nurses
}

Xuelin Zhang ${ }^{1, \mathrm{a}}$; Jun $\mathrm{Xu}^{2, \mathrm{~b}}$; Shouxia Chai ${ }^{1, \mathrm{c}}$; Meirong Lei ${ }^{1, \mathrm{~d}}$; Violeta Lopez ${ }^{3, \mathrm{e}}$

${ }^{1}$ School of Nursing, Hubei University of Medicine, 30\#Renming South Road, Shiyan city, Hubei Province, PRC,442000

${ }^{2}$ Taihe Hospital, Hubei University of Medicine, 32\# Renming South Road, Shiyan city, Hubei Province, PRC, 442000

${ }^{3}$ Alice Lee Centre for Nursing Studies, Young Loo Lin School of Medicine, Natonal University of Singapore, 10 Medical Drive, Singapore, 117597

a1040114891@qq.com, blauheart@163.com, ${ }^{\mathrm{c}} 44201040 @ q q . c o m,{ }^{\mathrm{d}} 365680322 @ q q . c o m$, enurvl@nus.edu.sg

Keywords: Correlation Research, Self - Efficacy, Job Alienation, Clinical Nurses

Abstract. Objective: To explore the relationship between the general self - efficacy and job alienation among clinical nurses in China. Methods: The Gerneral self - efficacy scale and the Work Alienation of nurse scale was used to investigate the clinical nurses in Shiyan City, Hubei Province. Results: The study showed that the self - efficacy and job alienation of clinical nurses were $(24.18 \pm 5.30)$ and $(34.22 \pm 7.02)$, General self - efficacy was related to job alienation negatively. Conclusion: The higher self-efficacy of clinical nurses was higher.

\section{Introduction}

Work alienation refers to the job situation cannot meet the needs or expectations of employees, leading to the separation of staff and the workplace, negative response to the work, low self-employed performance, low capacity utilization, low recognition of the work, resulting in increased turnover tendencies [1]. Self-efficacy was the core concept of American psychologist Bandura's social cognitive theory. Nurses' self-efficacy mainly refered to the confidence or belief that nurses need to acquire their own objectives in the field of nursing care [2]. The study explored the relationship between general self-efficacy and job alienation of clinical nurses, and provided theoretical support for improving the professional identity and job satisfaction of clinical nurses in hospitals.

\section{Method}

\section{Design and sample.}

Using convenience sampling method to investigate clinical nurses at affiliated hospitals in Shiyan City, Hubei Province from May to June 2016. Inclusion criteria: Registered nurses; engaged in clinical care for at least 1 year; voluntary participation in this study. Exclusion criteria: unregistered nurses; suffered major physical and mental illness; training nurses, interns nurses.

\section{Instruments}

The general self-efficacy scale consisted of 10 items, a single dimension, with a Likert-4 rating, with each items being scored from 1 to 4 points, the total possible scores ranged from 10 to 40 points, and the higher the score, the higher the efficacy [3], the Cronbach coefficient in this study was 0.875 . 
The Work alienation of Nurses scale: the scale was developed by Ren [4], including 12 items, three dimensions (helplessness, friendless, meaningless), 4 items in one dimension using Likert-5 Rating, each items from non-compliance to very consistence, the total possible score are 12-60 points, higher the score, higher the sense of work alienation. This scale was proved to be a good reliability and validity[4]. The Cronbach coefficient in this study was 0. 828.

General social-demographic profile, including age, gender, title, length of service, the degree of education, work, marriage and so on were asked to self-reported.

\section{Data Collection.}

Approval to conduct the study was obtained from the university internal review board and the affiliated hospital internal review board. The training research assistants explain the purpose and process of this study, ensure participant's right and privacy be protected, the data just used in this study. A convenience sample of 500 nurses participated in the study. However, of the 500 surveys completed, only 438 (87.6\%) were used in the final analysis due to missing data.

\section{Statistical Methods.}

SPSS24.0 software were performed to analysis, using the percentage, the mean standard deviation to descriptive analysis the social-demographic data, the general self-efficacy, work alienation score; $\mathrm{T}$ test and variance analysis were used to analysis the job alienation, Pearson correlation analysis were used to exam the correlation between general self-efficacy and job alienation. $\mathrm{P}<0.05$ was considered to be statistically significant in this study.

\section{Results}

The demographic information of Clinical Nurses The study included 438 subjects aged 20-55 years $(M=30.63 ; S D=6.89)$, in which 252 under the age of 3, all of them were women, in which 278 with junior professional rank, 136 with intermediate professional rank, only 24 people had senior professional rank. Most of the nurses obtained a college or undergraduate degree, 306 people had a bachelor's degree; 138 were single, and 300 people were married; nearly one-third of nurses' working experience were less than 5 years, 187 worked at the internal medicine Department, 171 worked at the surgical department, 80 worked at critical care in the hospital. See Table 1 for details.

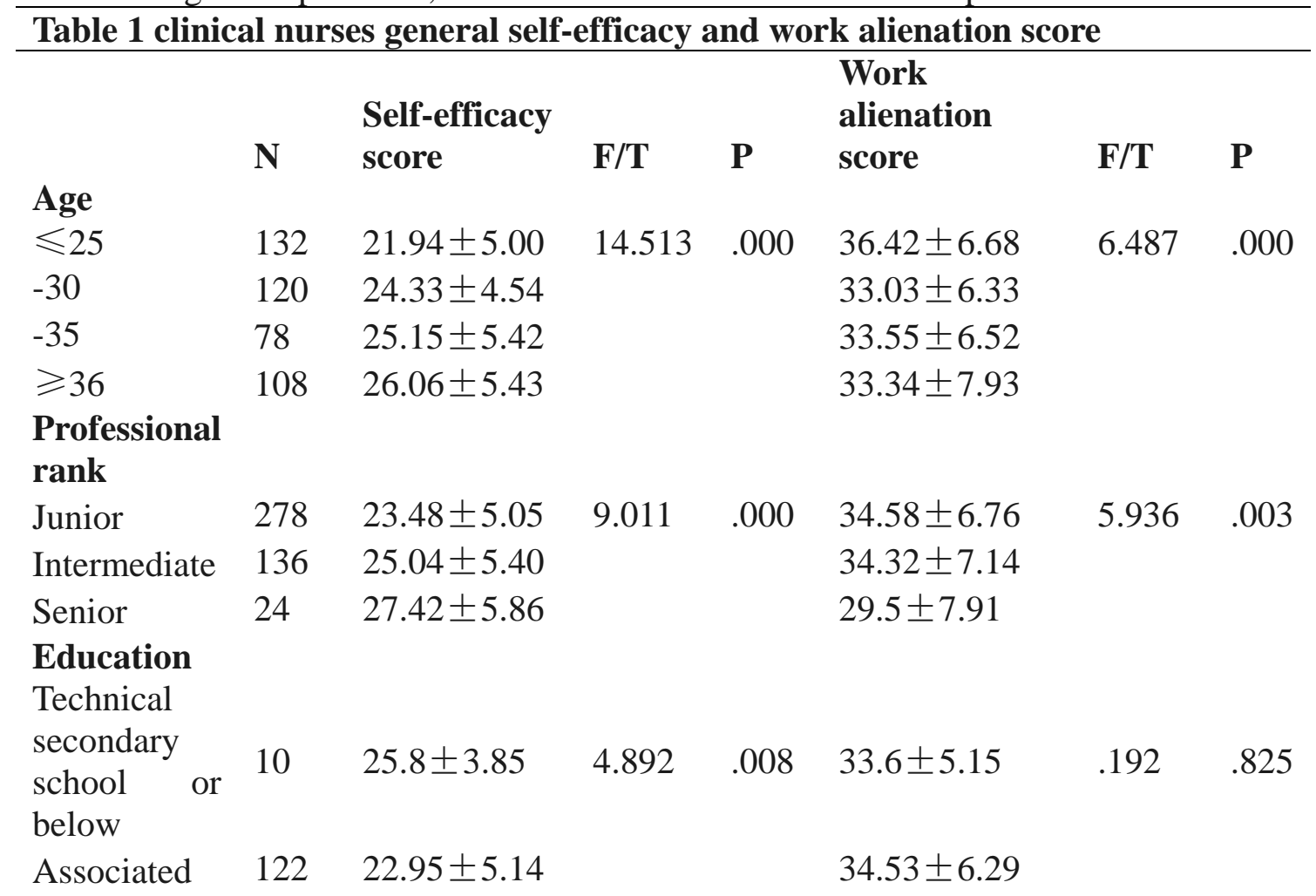




\begin{tabular}{|c|c|c|c|c|c|c|c|}
\hline $\begin{array}{l}\text { Bachelor or } \\
\text { above }\end{array}$ & 306 & $24.62 \pm 5.33$ & & & $34.12 \pm 7.35$ & & \\
\hline $\begin{array}{l}\text { Marital } \\
\text { status }\end{array}$ & & & & & & & \\
\hline Single & 138 & $22.12 \pm 4.99$ & -5.733 & .000 & $36.20 \pm 6.94$ & 4.063 & .000 \\
\hline Married & 300 & $25.13 \pm 5.18$ & & & $33.31 \pm 6.88$ & & \\
\hline $\begin{array}{l}\text { Years of } \\
\text { work }\end{array}$ & & & & & & & \\
\hline$\leq 5$ years & 170 & $22.72 \pm 5.1$ & 14.238 & .000 & $35.54 \pm 6.93$ & 10.666 & .000 \\
\hline 5-10 years & 98 & $24.08 \pm 4.94$ & & & $35.23 \pm 5.67$ & & \\
\hline >10 years & 170 & $25.7 \pm 5.30$ & & & $32.32 \pm 7.41$ & & \\
\hline Working & & & & & & & \\
\hline $\begin{array}{l}\text { Internal } \\
\text { medicine } \\
\text { system }\end{array}$ & 187 & $25.42 \pm 5.57$ & 5.663 & .004 & $33.93 \pm 7.36$ & 6.257 & .002 \\
\hline $\begin{array}{l}\text { Surgical } \\
\text { system }\end{array}$ & 171 & $24.74 \pm 5.08$ & & & $33.40 \pm 6.59$ & & \\
\hline $\begin{array}{l}\text { Acute and } \\
\text { critical }\end{array}$ & 80 & $22.43 \pm 4.80$ & & & $36.65 \pm 6.63$ & & \\
\hline Total & 438 & $24.18 \pm 5.30$ & & & $34.22 \pm 7.02$ & & \\
\hline
\end{tabular}

The Generally Self-Efficacy and Work Alienation of Clinical Nurses. The general self-efficacy score was 24.18 ( $\mathrm{SD}=5.31$ ), and average score of each items were $2.42(\mathrm{SD}=0.53)$. There was a statistically significant difference score of general self-efficacy among the different profile (age groups, professional rank, marital status, working years, nurses in different departments). The nurse work alienation score is $34.22(\mathrm{SD}=7.02)$, and average score of each items were $2.85(\mathrm{SD}=0.59)$. and the scores of the dimensions were: helplessness( $13.91 \pm 2.84)$; meaningfulness (11.09 \pm 3.68);friendless( $9.22 \pm 3.19)$. The results of univariate analysis showed that there were statistically significant differences in the alienation of clinical nurses in different age groups, different working years, different working years, different marital status and different departments, but the work of alienation of nurses with different qualifications there is no difference, see Table 1.

The correlation between General Self-Efficacy and the Job Alienation of Clinical Nurses. Pearson correlation analysis of general self-efficacy and job alienation and its dimensions was carried out. The results showed that the general self-efficacy was negatively correlated with the sense of alienation and its three dimensions (helplessness, friendless, meaninglessness). See Table 2.

\begin{tabular}{|c|c|c|c|c|c|}
\hline \multicolumn{6}{|c|}{$\begin{array}{l}\text { Table } 2 \text { The correlation between General Self-efficacy and work } \\
\text { alienation of clinical nurses }(N=438)\end{array}$} \\
\hline Self-efficacy & $\begin{array}{l}\text { Pearson } \\
\text { P Value }\end{array}$ & $\begin{array}{l}\text { Helplessness } \\
-.409 \\
.000\end{array}$ & $\begin{array}{l}\text { Friendless } \\
-.306 \\
.000\end{array}$ & $\begin{array}{l}\text { Meaningless } \\
-.412 \\
.000\end{array}$ & $\begin{array}{l}\text { Work } \\
\text { alienation } \\
-.520 \\
.000\end{array}$ \\
\hline
\end{tabular}

\section{Discussion}

The General Self-Efficacy of Clinical Nurse. In this study, the general self-efficacy score of clinical nurses was (24.18 \pm 5.30$)$, significantly lower than the norm [5] and the nurse level [6-8] (P $<0.01$ ), indicating that the level of self-efficacy of clinical nurses is low, nurses was lack of confidence to deal with the problem, the general self-efficacy of nurses needed to be further improved. Self-efficacy refered to the self-confidence of a person in a situation to complete a 
behavior [9], low self-efficacy would lead to nurses in the face of stressful events tend to negative judgments, leading to mental stress, lower job satisfaction [10 ]. In the current nursing work environment, clinical nurses were experienced highly physically and mentally exhausted, thus self-efficacy score was lower. The study found that: different age groups, different professional ranks, different education background, different marital status, different working years, nurses in different departments, the gerneral self-efficacy score were statistically significant difference. The clinical nurse with older age, higher professional rank, high education background, longer working experience, the general self-efficacy was higher, it may be because nurses work ability, work experience and social experience are constantly improved when getting older, so as to promote nurses general self - efficacy level. The results of this study were similar to Wang's [11]. The self-efficacy of the married person was higher than that of the single person, because the married person may be able to perceive more family support, thus promoting the improvement of self-efficacy. The results of this study were different from the results of Jiangping's [6],may be due to the relatively small age of this study population, married experience was short, perceived more support from the marriage, leading to a high level of self-efficacy; nurses working in the internal system wards had highest self-efficacy, and critically ill nurses Self-efficacy had the lowest, this situation may be due to acute and critically ill patients treated complex disease with a high risk work environment, resulting a great mental stress to nurses, the nurses self-efficacy were directly affect [6] , Therefore, different work wards affected the nurse's self-efficacy.

The Clinical Nurse Work Alienation. In this study, the clinical nurse's sense of alienation was 34.22 ( $\mathrm{SD}=7.02$ ), the scores of the dimensions were: helplessness( $13.91 \pm 2.84$ ); meaningfulness (11.09 \pm 3.68$)$;friendless( $9.22 \pm 3.19)$. The highest scores was helplessness and the lowest scores was friendless. Unsafe factors had a significant impact on job alienation [12]. Clinical nurses face patients and families every day and were exposed to severe medical settings which is fast-paced, heavy-duty, high-risk, low-paid working environment. With the insecurity of the organizational atmosphere and the insecurity of the employee's behavior, the clinical nurses worked with many restrictions, felt cannot independently control the work, loss of control, resulting in their social needs cannot be met, so that they felt the desired personal goal cannot achieve or feel the work valueless, resulting high level of job alienation. High level of work alienation lost control of work often resulting from a alienated negative work environment and experience. This study found that there were statistically significant differences of work alienation regarding different age, different professional rank, different working years, different marital status and different departments (P $<0.05$ ), but there was no statistically significant difference among nurses with different education background. With age, clinical nurses would increase in clinical experience, when they faced the clinical conflict, they can quickly adapt and can provide a professional and safe response in the complex medical environment for the patient, would finally complete the work successfully. And with the seniority, the professional rank, clinical nurses enhanced the ability of self-control, ability of time management, their self-worth would also increase greatly. Thus they had more chance to get promotion, obtain learning or training opportunities, the responsible for teaching, research, quality control which they took were increasing, which guarantee higher enthusiasm at work and higher satisfactions were obtained from patient, higher recognition of work, relative positive experience. So that the work experience and professional rank affected the work alienation of clinical nurses[13], this findings was same as the study of Ren[4] . The sense of alienation of single nurses was higher than that of married persons, which was consistent with the results of research [4], which may be due to the lack of social support for marriage when single nurses respond to job alienation. In this study, nurses who work in the internal medicine department have the lowest sense of alienation, and the nurses in the critically ill patients are the highest alienated, possibly due to the different characteristics of the patients who in the critically wards. This study found that the education background of clinical nurses would not affect the job alienation significantly, the results of Ren [4] was inconsistencies, the possible reason was this study's population was different, which were older, higher professional rank, lower academic education background.

This study showed that helpless feelings of clinical nurses was the highest dimension of job 
alienation, may be due to clinical nurses work under the strict supervision, nurses feel tired easily, so feel helpless ; Meaninglessness of clinical nurses was lower, probably because the nurses spend a lot of time and effort comparing with the doctor, the chance of promotion, development were relatively little, it was difficult to achieve their own value, resulting in meaningless; nurse friendless is scored lowest, may be because the clinical nurses obtain timely help from colleagues or leaders when they provide care to patients.

The correlation of General Self-Efficacy and Job Alienation. The results of this study showed that general self-efficacy had a negative moderate correlations with job alienation and the three dimensions, see Table 2. This study indicated that the higher the general self-efficacy, the lower the job alienation of clinical nurse, psychological separation and behavior of alienation was better improved when they feel they were able to control. Self-efficacy can be mediating variables that regulate external environmental factors and personal emotional states. Studies have shown that job requirements can lead to lower individual achievement through general performance. [14] High self-efficacy nurses were willing to try challenging work can actively deal with the conflict in the work, willing to try new methods or skills, work a higher level of input, job performance better [15]; and nurses lack of self-efficacy suspected that their handling, control the scene, The ability to respond to negative behavior was passive [16], felt their own value was difficult to achieve more and more, work meaningless increased also; because of low self-efficacy, was not willing to communicate with colleagues, it was difficult to get colleagues or leadership care and Help, increased work helplessness; clinical nurses self-efficacy was low, the lack of self-confidence in the completion of the work reduced the level of control, make nurses feel tired easily [15], leading higher helpless of work.

\section{Conclusion}

This study found that the general self-efficacy and alienation of clinical nurses were at a moderate level, and the general self-efficacy was negatively correlated with the sense of alienation, suggesting that nursing managers should pay attention to the general self-efficacy and job alienation of clinical nurses. The general self-efficacy of clinical nurses, such as through the clinical nurses feel successful, asynchronously, respect for support, etc., targeted nurses for self-efficacy training, strengthen their correct attribution, improve their Self-efficacy level, so as to reduce the clinical nurse's sense of alienation, and ultimately promote the quality of clinical care and nursing team stability.

\section{Acknowledgements}

Fund Project: Hubei university of medicine talents startup 2013QDJRW07 project

\section{References}

[1] Zhou Hao, Long Lirong. Review of the study of alienation [J]. Advances in Psychological Science, 2011,19 (01): 117-123. [2017-08-27].

[2] Jiang Ping, Zhao Chunfang, Han Lanping, Wu Jing, Deng Guanghui, Zhang Wei. Hospital nurses self-efficacy survey and related countermeasures [J]. Chinese Medical Innovation, 2012,9 (15): 78-81 [2017-08-27].

[3] Zhang, JX, Schwarzer, R. Measuring optimistic self-beliefs: A Chinese adaptation of the General Self-Efficacy Scale. Psychologia: An International Journal of Psychology in the Orient, 1995, 38 (3), 174-181

[4] Ren Xiaojing. Nurse's work of alienation of the content structure and related research[D]. Henan University, 2012 
[5] Zhang Zuji. Behavioral Medical Scale Manual[M]. Beijing: Chinese Journal of Behavioral Medical Science. 2001: 185-186.

[6] Jiang Ping, Zhao Chunfang, Han Lanping, Wu Jing, Deng Guanghui, Zhang Wei. Hospital nurses self-efficacy survey and related countermeasures [J]. Chinese Medical Innovation, 2012,9 (15): 78-81

[7] Chen Guijie. Specialist male nursing students self-efficacy status and influencing factors investigation and analysis [J]. Journal of Nursing Science, 2010, 16 (21): 43-45.

[8] Qiu Dongyou, Liu Xiuru, Yu Chanhua. Low age nurses mental health status analysis [J]. Nursing Journal, 2003, (10): 753-754

[9] Bandura A. Self-efficacy: Toward a unifying theory of behavioral change [J] .Psvchological Review, 1977, 84 (1): 191-215.

[10] Chen Yue, Zhang Hongchen. Nurses general self-efficacy research progress [J]. Nursing practice and research, 2013,10 (02): 134-135.

[11] Wang Lan, Qin Yi, Wang Qun. Clinical nurses self-efficacy and influencing factors [J]. Nursing Research, 2008, 22 (12): 3303-3305.

[12] Taamneh M, ALgharaibeh SMA. The Impact of Job Security Elements on the Work Alienationat Private university in Jordan (A Field Study from Employees perspective)[J]. European JournalBusiness and Management, 2014, 26 (6): 56-68

[13] Temel C, Mirzeoglu N, DilsadMirzeoglu A. An investigation of physical education teachers' work alienation Level according to some variable [J] .International Journal of Academic Research, 2013, 5: 502-508

[14] Li Zhihong, Ren Xuming, Lin Lin, Shi Kan.Evaluation of teaching efficacy and teacher work stress and job burnout [J]. Journal of Psychology, 2008, (01): 218-221

[15] Jin Yinghua, Shi Shasha, Cui Wenxiang. The influence of head nurses 'empowerment on clinical nurses' self-efficacy and work control[J]. Chinese Journal of Nursing, 2014,49 (01): 104-107

[16] Yang HL,haoYH,Huang YC.The job self-efficacy and job involvement of clinical nursingteachers[J].Journal of Nursing Research,2006,14(3):237-249. 